DOI 10.5216/ia.v45i3.64346

\title{
POSSIBILIDADES DE FORMAÇÃO DE UMA IDENTIDADE FEMININA A PARTIR DAS PÁGINAS DO JORNAL DIÁRIO DOS CAMPOS - 1910 A 1930
}

\author{
Karina Regalio Campagnol \\ Universidade Estadual de Ponta Grossa (UEPG), Ponta Grossa, Paraná, Brasil
}

\begin{abstract}
Resumo: O objetivo deste artigo é discutir a formação de uma identidade feminina por meio da análise das publicações do jornal Diário dos Campos, periódico pontagrossense centenário, abordando o contexto histórico das décadas de 1910 a 1930. A partir de análise documental, com abordagem qualitativa, procurou-se compreender como as reportagens, artigos e demais matérias do referido jornal dirigiam-se às mulheres, refletindo sobre as possibilidades de formação oportunizadas ao público feminino neste contexto histórico específico. Constata-se que o engajamento e empoderamento femininos evidenciados neste periódico ocorreram apenas para uma parcela pequena das mulheres, ou seja, as que possuíam capital econômico, cultural e social, com a conformação de alguns habitus que favoreceram esses comportamentos.

Palavras-chave: Educação das mulheres. Gênero feminino. Educação. Formação feminina.
\end{abstract}

\section{INTRODUÇÃO}

O objetivo deste texto é discorrer sobre o processo de formação de uma identidade feminina a partir da análise das matérias, artigos e anúncios vinculados pelo jornal Diário dos Campos $^{1}$ durante as três primeiras décadas do século XX, enfatizando a disputa pelos espaços públicos tradicionalmente masculinos, procurando relacionar suas contribuições com a educação e com as oportunidades oferecidas pelo acesso ao campo do conhecimento e da cultura.

O caminho metodológico baseia-se na análise documental, com uma abordagem qualitativa. As fontes de pesquisa foram os arquivos do jornal Diário dos Campos, os quais encontram-se em formato digitalizado na Casa de Memória, referente às décadas de 1910 e 1920, e no formato físico no Museu Campos Gerais, referente à década de 1930, espaços estes localizados na cidade de Ponta Grossa - Paraná.

Procurou-se compreender a atuação das representantes do gênero feminino e suas relações com o jornal Diário dos Campos como manifestações das mulheres

1 O jornal Diário dos Campos, também conhecido como DC, inicialmente intitulado como O Progresso, é um periódico centenário da cidade de Ponta Grossa - Paraná, constituindo-se por um longo período como o único veículo de comunicação impressa dos Campos Gerais, região geográfica à qual Ponta Grossa faz parte. Neste artigo, utilizaremos os termos Diário dos Campos e DC como sinônimos. 
enquanto sujeitos históricos, elencando o conceito de gênero como chave de análise para a compreensão do envolvimento das mulheres nos mais diversos cenários públicos, a partir da conceituação sugerida por Scott (1995). Nessa perspectiva, "o gênero é um elemento constitutivo de relações sociais baseadas nas diferenças percebidas entre os sexos e o gênero é uma forma primária de dar significado às relações de poder" (SCOTT, 1995, p. 86). Além disso, enfatizam-se os aspectos que fizeram menção ao papel social da mulher por meio da educação e da tomada de posição política, procurando-se elucidar as redes sociais de contato, assim como as conjunturas que lhes possibilitaram condições de enfrentamento em direção à construção de um habitus ${ }^{2}$ feminino.

O uso do jornal como fonte pode ajudar a compreender as relações entre as mulheres e as diversas modalidades de sua formação e autoformação. Sobre isso, Vieira (2007, p 38) registra que a pesquisa por meio de jornais possibilita compreender que "A educação, a política, a economia, por exemplo, dizem respeito à sociedade, seja como parte do processo de formação da posição ideológica dos sujeitos, seja como condição pragmática de existência dos indivíduos. [...]".

Assim, ao considerarmos o jornal como veículo de comunicação, como um modo de se propagar ideias e concepções, defendemos a compreensão dessa fonte de pesquisa como formadora de um habitus, gerando disposições sociais que são incorporadas de formas distintas, especialmente pelas mulheres.

Iniciamos nossa análise salientando que muitas das notícias e reportagens sobre as mulheres veiculadas pelo DC geralmente estavam dispostas em notas pequenas e de pouco apelo visual dentro da diagramação do jornal. Além disso, em relação à constituição da equipe editorial do jornal Diário dos Campos durante o período analisado, destaca-se que encontramos registros apenas de homens que exerciam a função de editores. Algumas poucas mulheres ocuparam espaços no DC enquanto autoras, porém isso se deu de forma pulverizada nas primeiras décadas do século XX.

Desse modo, para fundamentar as problematizações apresentadas neste artigo, foram mobilizadas as contribuições de alguns autores, como: Perrot (1998), Scott (1995), Bourdieu $(1989 ; 2008 ; 2017)$, entre outros.

\section{FORMAÇÃO DAS MULHERES A PARTIR DA PRESCRIÇÃO MASCULINA}

Muitos dos apontamentos observados nesta pesquisa nos levam a considerar que o jornal Diário dos Campos, durante o período analisado, considerava a mulher majoritariamente como leitora, ao invés de autora. Assim, o periódico direcionava muitas de suas publicações a esse público específico, na forma de textos, poesias, conselhos, mas também como propagandas de produtos e serviços, conforme também observado pelas pesquisas de Perrot (1998) e Santos (2011). Isso fica estampado, por exemplo, em uma publicação específica, de autoria de Gonçalves Crespo, veiculada no

\footnotetext{
2 De acordo com Bourdieu (2008), o conceito de habitus remete a uma configuração nos gostos, nas preferências, nas opções, nos comportamentos, nas posturas, entre outras características de um agente.
} 
jornal Diário dos Campos em 26 de novembro de 1921, em que a reportagem dirigia-se "À mais gentil leitora desta secção [...]".

Dessa forma, sempre enaltecendo a relevância da escolarização e da formação educacional e cultural de forma geral, o DC demonstrou, pelo menos no período analisado, um compromisso em publicar variadas notícias que se referiam à educação em Ponta Grossa e também na região dos Campos Gerais, enaltecendo os feitos de seus dirigentes e professores, entre os quais destacavam-se os nomes de algumas mulheres, reafirmando os investimentos em educação como símbolos de civilização e modernidade.

Sobre isso, pode-se citar o caso de uma notícia sobre o "Collegio Pontagrossense", instituição particular que na data da reportagem, 08 de agosto de 1923, era conduzida pela professora Esther Ferreira Ribas. A notícia assinala que essa educadora havia elaborado um "livrinho" com músicas para seus alunos. $\mathrm{O}$ jornal ainda destaca que esse livro trazia o Hino Nacional e a "Canção da Escola", esta última havia sido composta por José Cadilhe, editor do Diário dos Campos nos anos de 1920. Essa reportagem demonstra a valorização da "missão" da escola pelo periódico, especialmente no sentido de salientar o intenso nacionalismo propagado nesse contexto. Além disso, a reportagem demonstra a boa interlocução que havia entre as docentes que atuavam na cidade e a equipe masculina que compunha o editorial do DC, conforme discutiremos na sequência.

Nesse sentido, muitas foram as notícias veiculadas pelo jornal Diário dos Campos que salientaram a figura feminina, defendendo que as mulheres foram de fundamental importância para o desenvolvimento educacional no Brasil nas primeiras décadas do século XX, enquanto professoras das "primeiras letras". No entanto, devemos considerar que grande parte da participação feminina no Diário dos Campos surgia apenas como temática, ou seja, eram os homens que escreviam para elas ou sobre elas.

A partir dessa ótica e da compreensão do jornal enquanto meio não institucionalizado de formação das mulheres, dentre as concepções vigentes sobre o gênero feminino que circularam abertamente no DC, destaca-se o chamado "fingimento feminino", concepção apresentada pelo periódico em muitas edições. Como exemplo disso, na edição do dia 03 de dezembro de 1932, a coluna "Notas Mundanas" título "As Evas e os Adões", trouxe uma crítica bastante ácida às mulheres, alegando que desde o tempo de "Eva" elas eram falsas e dissimuladas. Colaborando neste debate, a autora Norma Telles (2019), ao pesquisar as representações associadas à imagem das hienas, descobriu que elas eram vinculadas desde longo tempo a indivíduos ambíguos e desleais. E dentre essas classificações, destacavam-se as mulheres.

Seguindo esse modelo de formação pautado nas referências à imagem do gênero feminino como pouco confiável e volúvel, em outra matéria do jornal Diário dos Campos, publicada em 20 de maio de 1933, o título "Hypocrisia de mulher" também trazia esse ideário, já possível de ser observado a partir de seu próprio título. Além disso, em algumas edições do DC as concepções que expressavam a "dominação masculina", conforme terminologia adotada por Bourdieu (2017) em seu livro de mesmo título,

\footnotetext{
3 "As colunas 'Notas Mundanas' e 'Locaes' eram espaços destinados pelo Diário dos Campos para informar aos leitores sobre fatos do cotidiano ponta-grossense. [...]". (CHAVES, 2001, p. 42).
} 
foram publicadas pelo jornal, retratando, assim, as características desse período histórico em que as mulheres ainda lutavam por alguns direitos atualmente já estabelecidos, como: votar; escolher a profissão desejada; viajar sozinha; casar com alguém escolhido por elas mesmas; divorciar-se sem precisar de motivo; não casar se assim desejar; ter filhos, não tê-los, entre outras situações. Com isso, não pretendemos indicar que as disputas femininas já alcançaram todos os níveis ideais nos dias atuais, pois as mulheres ainda lutam para serem tratadas com dignidade, no entanto muitos avanços já ocorreram.

Nesse sentido, em diversos momentos o DC mostrou-se contraditório em relação aos aspectos que diziam respeito ao universo feminino, pois algumas vezes 0 periódico demonstrou simpatia e apoio às causas femininas, denunciando abusos e violências, além de comemorar com as mulheres as vitórias e progressos em todos os campos sociais em que elas, aos poucos, iam abrindo espaço. Por outro lado, em algumas situações, o DC também acabou promovendo a legitimação da arbitrariedade masculina, conforme termos de Bourdieu (2017), por meio da veiculação de reportagens e artigos que, de forma geral, defendiam o ideário de boa mãe e de esposa exemplar. No entanto, no campo público o DC procurou manifestar as concepções que iam se delineando no Brasil e no mundo sobre a presença cada vez maior de mulheres nos cenários culturais e políticos.

Dessa forma, ao procurar se mostrar atualizado, acompanhando a pauta das principais cidades do Brasil e da Europa e caracterizando-se, assim, como um porta-voz dos novos tempos, o DC em muitos momentos posicionou-se em defesa da educação, seja a escolar (grupo escolar, Escola Normal), seja a não escolar (representações do papel feminino), lançando-se como um dos principais protagonistas da história de Ponta Grossa e dos Campos Gerais. No entanto, o Diário dos Campos não carregou uma bandeira de exclusividade da educação feminina. Porém, a temática das mulheres integrava a construção da cidade de Ponta Grossa, uma vez que a elas estavam reservadas as funções de professora, especialmente na interlocução com a Escola Normal, no sentido de que a educação estava alinhada às ideias de modernização e urbanização.

\section{PROCESSO DE FORMAÇÃO DA IDENTIDADE FEMININA A PARTIR DE SUAS PRÓPRIAS} EXPERIÊNCIAS

A partir da compreensão do papel do Diário dos Campos enquanto possibilidade de instrumento de formação, considerando o processo de educação feminina tomada em um sentido amplo, abrangendo não somente a educação formal e escolarizada mas também os aspectos culturais, observamos um movimento das mulheres, especialmente nos anos de 1930, em direção a um posicionamento mais emancipado.

Dessa forma, nossa pesquisa demonstra um processo de conformação de um padrão mais progressista e ousado, delineado a partir de mulheres que, paulatinamente, foram se inserindo em outras profissões além da docência, circulando em diversos 
espaços culturais, protagonizando espetáculos artísticos e buscando novas atuações sociais. Assim, o recorte temporal de nossa pesquisa justifica-se pela relevância que as primeiras décadas do sistema republicano no Brasil conferiram ao papel desempenhado pelas mulheres, considerando-as como os sujeitos ideais para conduzirem o ensino das primeiras letras (OLIVEIRA, 2018). Essa aposta no papel primordial das mulheres pode ser representada pela criação da Escola Normal em Ponta Grossa, em 1924, e também pelas discussões nacionais e internacionais que ocorriam em torno dos chamados novos direitos femininos.

Nesse sentido, um ponto importante que favoreceu a entrada das mulheres no mundo da cultura e da educação foi a formação de grupos femininos, inclusive no sentido do potencial formativo dessas agremiações formadas exclusivamente por mulheres. Nessas comunidades, elas dispunham de espaço para discutir questões da sociedade, trocar impressões e organizar ações encabeçadas por elas mesmas. Em Ponta Grossa, a Associação das Damas de Caridade talvez se configurasse como uma forma aproximada desse tipo de instituição, uma vez que em diversas oportunidades o Diário dos Campos noticiou os eventos promovidos pelas associadas com o objetivo de angariar fundos para suas causas, como a veiculada na edição de 08 de junho de 1932 . Nessa reportagem, o DC salienta que entre as participantes mais assíduas destacavamse: Adelina Buffara, Nene Oliveira, Maria Bacila, Ermina Justus, Emma de Macedo, Maria Sophia G. Villela, Balbina G. Cunha, Adalgisa Macedo, Olga C. Bach, Carlota C. Prestes, Noemia Nogueira, Amelia M. Ribas, entre outras (DC, 08/06/1932). O ponto em comum entre essas mulheres é que todas elas eram detentoras de alguma espécie de capital ${ }^{4}$, como o econômico, o social, o cultural e o simbólico, geralmente representado de forma cumulativa e combinada.

Perrot (1998) e Trindade (1996) destacam que principalmente as senhoras das camadas mais abastadas da sociedade eram as que mais se envolviam com essas questões, a exemplo das senhoras que compunham a associação que citamos no parágrafo anterior. Sobre isso, podemos discutir que possivelmente o acúmulo de capital em suas diversas formas tenha possibilitado que algumas mulheres pudessem exercer atividades fora do lar, tendo condições para se expressar em ambientes públicos e buscar novas posições sociais.

Essas agremiações, compreendidas especialmente no sentido de formação e autoformação femininas, foram importantes para a constituição das mulheres enquanto grupo social. Uma combinação importante desses grupos femininos foi a que se unia à filantropia, representada pelas ações dessas mulheres em prol dos menos favorecidos, conforme observado por Mott (2003) e Martins (2017). Trindade (1996, p. 256) também corrobora nossos achados de pesquisa ao apontar que, "as associações filantrópicas são,

${ }^{4}$ De acordo com Bourdieu (1989), o conceito de capital apresenta 4 subtipos, a saber: capital social, econômico, simbólico e cultural. O capital social pode ser representado pelas amizades, contatos e relacionamentos. O capital econômico diz respeito aos bens, imóveis, joias e demais itens de valor financeiro. Já o prestígio, respeito e reconhecimento fazem parte do capital simbólico. O capital cultural pode ser compreendido a partir de 3 subdivisões: capital cultural objetivado, incorporado e institucionalizado. Os livros, obras de arte e demais objetos concretos dizem respeito ao capital cultural objetivado. Já o modo incorporado remete a uma postura própria do indivíduo, como se fosse parte do agente, segundo nomenclatura de Bourdieu. Os títulos escolares e acadêmicos fazem menção ao capital cultural na forma institucionalizada. 
enfim, um recurso de que lançam mão as mulheres ao se verem privadas do exercício mais ativo de sua cidadania, utilizando-as como elo entre o mundo doméstico e certa participação social e política".

Assim, esse novo habitus feminino coincide com algumas das discussões que se desenvolviam na sociedade daquela época sobre vários temas, pois, além do voto, debatiam-se assuntos como o divórcio, a inserção das mulheres em profissões tradicionalmente masculinas, como a aviação, o universo militar, a participação em júris populares, entre outras situações. Observou-se no Diário dos Campos muitas reportagens em direção à construção da mulher como cidadã, a partir da compreensão de Botelho e Scharcz (2013) sobre cidadania, no sentido de participação política e tomada de decisões.

Essas questões remetem ao que Perrot (1998) discute sobre as mulheres públicas e as do ambiente privado, salientando as diferenças historicamente construídas entre os gêneros feminino e masculino. Em nossa pesquisa, pudemos constatar que a educação para as mulheres possibilitou essa oportunidade de vivência pública, especialmente a partir da criação da Escola Normal em Ponta Grossa em 1924, abrindo espaço de expressão no DC para muitas mulheres a partir dessa data, em comparação com o período imediatamente anterior.

Assim, ao considerarmos o capital cultural como aspecto relevante na análise sobre o processo de formação feminina no jornal Diário dos Campos, constatamos uma grande quantidade de referências a esses quesitos, propalados pelo referido periódico por meio da propaganda de filmes, peças de teatro, apresentações musicais, entre outras modalidades culturais. Sobre isso, é importante salientar que em muitos desses anúncios e artigos jornalísticos as mulheres surgiam também como protagonistas, atuando nas mais variadas áreas, como poetisas, atrizes, cantoras, musicistas, entre outras atividades culturais. Além disso, ao fazermos relação com a criação da Escola Normal em Ponta Grossa, podemos supor que o maior acesso ao universo educacional, primeiramente como alunas e posteriormente como professoras, diretoras, secretárias, entre outras ocupações relacionadas à área da educação, possibilitou novas oportunidades culturais para essas mulheres (TELLES, 1989; DUARTE, 1990).

No universo cultural do cinema, muitas foram as referências do Diário dos Campos às mulheres durante todo o período analisado. Em um exemplo marcante, na edição de 04 de dezembro de 1932, o DC retrata a propaganda do filme "Mulher sem algemas", numa clara alusão às lutas do gênero feminino pela conquista de direitos. Esse filme apresentava uma concepção bastante ousada para o contexto dos anos 1930, pois o enredo baseava-se no relacionamento de um casal que não possuía uma união oficial, algo bastante condenado para a época, tanto que eles acabam cedendo às influências sociais e casam-se formalmente (CINE PLAYER, s/d).

Dessa forma, os títulos de alguns dos filmes apresentados demonstram que as questões que se relacionavam com o gênero feminino estavam em voga na sociedade, especialmente nos anos de 1920 e 1930, sendo o cinema e o teatro, juntamente com o jornal impresso, algumas das formas de discussão e circulação de ideias acerca desses assuntos. Sobre isso, Almeida e Soares $(2012$, p. 565) afirmam que: 
CAMPAGNOLI, K. R.

\begin{abstract}
Nos anos 1940/50, em seguimento aos anos iniciais do século XX, o pensamento feminista encerrava a proposta de possibilitar para as jovens o acesso à educação, juntamente com o direito ao voto, porém não se questionava seu papel de esposas e mães. Nesses anos, na esfera cultural, o cinema, as revistas, a televisão, o rádio, (como hoje), impregnavam a cultura e influenciavam nos modos de pensar individual e coletivo. O imaginário de Hollywood traçava os padrões e se estendia a todos os que tinham acesso à exibição nas telas, desde os anos iniciais do século, estendendo-se para as décadas seguintes [...].
\end{abstract}

O campo da música também foi bastante explorado pelo Diário dos Campos, que estampou frequentemente em suas páginas entrevistas e anúncios das atividades desse âmbito que seriam realizadas em Ponta Grossa. Muitas musicistas fizeram parte dessas reportagens, como o anúncio sobre o concerto que "D. Aida Poggetti" realizaria na cidade (DC, 21/12/1921). Interessante destacar que o Diário dos Campos enfatiza a graciosidade da voz de Aida Poggetti e seu porte elegante, revelando novamente a feição de um habitus feminino ligado às artes musicais, aqui, no caso, à música erudita e também à feminilidade, característica muito valorizada em uma mulher nesse contexto. Esses aspectos também foram observados por Freire e Portella (2010), ao pesquisarem musicistas em um contexto histórico similar ao nosso.

Especialmente sobre o universo das letras é importante destacar, dentre as poucas autoras que contribuíram com o DC no período pesquisado, uma relevante exceção a essa situação. Trata-se da poetisa e escritora Anita Philipovsky, famosa autora ponta-grossense, possuidora de condições financeiras favoráveis provindas de sua família, condições estas que the possibilitaram uma educação esmerada (OLIVEIRA, 2018). Nossa pesquisa demonstra que Anita sempre lutou por seu espaço social e público, conseguindo apoio dos editores do Diário dos Campos e posteriormente colaborando com outros periódicos, conforme pode ser averiguado pela transcrição da notícia a seguir sobre uma reportagem de 01 de junho 1921, em que o Diário dos Campos $^{5}$ comenta sobre os elogios tecidos à "Annita Philipowsky" pelo periódico "A República", da cidade de Curitiba, regozijando-se de ter publicado os primeiros textos de Anita.

\begin{abstract}
"A Republica" noticiando a estada da distincta escriptora pontagrossense na capital, tecem-lhe os mais justos e merecidos elogios. Annita Philipowsky não é apenas uma impressionista de supercialidades, como em regra são as escriptoras. Annita Philipowsky pensa, philosòpha, e aborda questões sociaes com superioridade vistas. [...]. Nòs que Ihe acompanhamos os primeiros passos [...] temos muito prazer registrando esta noticia [...]. (DC, 01/06/1921).
\end{abstract}

A participação da ponta-grossense Anita Philipovsky nas páginas do jornal Diário dos Campos pode ser considerada como um exemplo feminino singular, uma vez

\footnotetext{
${ }^{5}$ Optamos por manter a grafia original apresentada por nossa fonte de pesquisa, o jornal $\mathrm{O}$ Progresso/Diário dos Campos.
} 
que a maioria das referências a mulheres no $D C$ vinha de reportagens e notícias de outras localidades. No entanto, esse detalhe apresenta relevância, pois com essa prática o jornal Diário dos Campos acabava compartilhando as ações de mulheres de outras regiões, fazendo circular, portanto, ideias e possibilidades para as representantes do gênero feminino de Ponta Grossa e arredores, comportando-se assim como um instrumento formativo para as leitoras do Diário dos Campos.

Outras poetisas também colaboraram de forma tímida e pouco frequente com o jornal Diário dos Campos. Geralmente suas temáticas abordavam o campo dos sentimentos, universo até então considerado apropriado para as mulheres, pela associação à tão difundida fragilidade feminina. Em uma dessas publicações, veiculada na edição de 27 de outubro de 1923, no poema intitulado "Duvida", Virginia Victorino discorre sobre o amor, fazendo jus a esse conhecido habitus feminino que consiste em refletir sobre os sentimentos humanos (WOELLNER, 2007).

Celina - mencionada pelo DC apenas por seu primeiro nome - era outra poetisa que participava com certa frequência das páginas do Diário dos Campos. $\mathrm{Na}$ edição de 28 de junho de 1921, Celina dedica uma de suas produções a José Cadilhe, editor do DC e grande mediador entre as mulheres autoras e professoras e o jornal Diário dos Campos, intitulado "Alouette: Ao Rostand ${ }^{6}$ paranaense J. Cadilhe". Nesse poema, Celina chama José Cadilhe de pássaro, exaltando sua liberdade e alegando que admirava seus escritos. Talvez Celina se referisse à liberdade literária que Cadilhe, enquanto homem, poderia usufruir, ao contrário dela que, enquanto mulher, ainda precisava tencionar os limites impostos ao gênero feminino para poder escrever com liberdade. Depois dessa homenagem, o próprio Cadilhe também dedica uma produção sua, intitulada "Talento", à poetisa Celina, elogiando sua capacidade literária e demonstrando apreço por seus predicados intelectuais, ressaltando sua modéstia e fazendo referência a um habitus bastante admirado na postura das mulheres nesse contexto, conforme já destacamos.

O agradecimento pela colaboração das mulheres ao Diário dos Campos com artigos e poesias foi exposto em alguns momentos. Além do que já mencionamos, nossa pesquisa encontrou outra homenagem que foi endereçada à autora Anita Philipovsky, por meio do texto intitulado "O carinho". Este tributo foi escrito por Antonio L. Albuquerque, editor do DC na época, como uma demonstração da amizade dos editores do Diário dos Campos para com Anita, impresso com o qual ela muito contribuiu nas primeiras décadas do século XX. Essa reportagem, veiculada em 08 de agosto de 1924, valorizava os escritos de Anita, posicionando-a como uma das representantes das mulheres autoras de Ponta Grossa.

A partir dos conceitos de capital social e simbólico, cunhados por Bourdieu (1989), podemos compreender que essas amizades, pautadas no respeito e na admiração mútuos, possivelmente colaboraram para aumentar a circulação das mulheres pelo universo letrado, representado aqui pelo jornal Diário dos Campos, tencionando alguns padrões impostos às mulheres.

\footnotetext{
${ }^{6}$ Rostand referia-se ao poeta e dramaturgo francês Edmond Eugène Alexis Rostand.
} 
A construção e manutenção dessas redes sociais, representadas pelas boas interlocuções femininas com os editores do Diário dos Campos, possivelmente facilitaram a inserção de Anita Philipovsky também como crítica social, conforme pode ser constatado pelo excerto a seguir, quando o DC ainda se chamava O Progresso, em um artigo em que ela questiona as oportunidades de estudos para as moças de Ponta Grossa:

\begin{abstract}
Nós moças de Ponta Grossa, que fontes tivemos e temos para saciar nossa sede de saber? Em uma escola de primeiras letras recebíamos o ensino das matérias elementares, e este mesmo interrompido pelos impedimentos da professora, e nada mais [...]. Quando se abrio o instituto "Dr. João Candido", em nossa cidade podia estabelecer se também um curso secundário para meninas ensinando com especialidade geografia geral, eletricidade, escripturação mercantil, contabilidade, tachigrafia e uma das línguas mais geralmente faladas como a franceza, inglesa ou allemã. Ficariam, com o preparo nessas matérias, habilitadas para ocuparem cargos no correio, telegrapho, telephone, ou como guarda livros e correspondentes commerciaes [...]. (O Progresso, 08/08/1912).
\end{abstract}

No excerto acima, Anita Philipovsky aponta a impossibilidade das mulheres em seguir com os estudos em Ponta Grossa, denunciando como insuficiente a oferta das chamadas "primeiras letras". Além disso, Anita questiona a possibilidade de se oferecerem "cursos secundários" para as moças, no sentido de formação das mulheres para que pudessem garantir seus sustentos por meio do próprio trabalho, defendendo, assim, a autonomia feminina. Sobre isso, Anita ainda afirma que as mulheres deveriam ter mais opções profissionais, indo além da já consolidada ideia de vocação para atuar como "professora primária".

Além de Anita Philipovsky, no Diário dos Campos, as representantes da Escola Normal também estiveram presentes nas atividades culturais publicadas pelo jornal, especialmente a partir de 1924, constituindo-se o DC como um espaço de diálogo entre as docentes e a sociedade, especialmente em relação à ala feminina. Em uma oportunidade, as professoras Maria Eulina Schena, Ida Bentim de Lacerda e Arminda Frare elaboraram uma publicação intitulada "A Escola", denominada pelo DC como "órgão litero-pedagógico" da Escola Normal. Nessa reportagem, denota-se a relevância dessa instituição para o DC, a contar pela frequência com que este impresso veiculava notícias sobre essa escola e também pela forma de escrita respeitosa do DC, confirmando nossa afirmação de proximidade e amizade entre os editores e as professoras, ao referir-se como "nossa Escola Normal" (DC, 16/08/1933).

Um ponto em comum entre as mulheres retratadas até aqui é que praticamente todas possuíam alguma forma de capital. Especificamente no caso de Anita Philipovsky, é importante salientar que sua família era detentora de capital cultural, social, econômico e simbólico. Isso nos leva a refletir que, de forma geral, as mulheres que estampavam as páginas do jornal Diário dos Campos, tanto como autoras quanto como atrizes, musicistas ou vinculadas a movimentos culturais de ordens diversas, eram mulheres que possuíam, de uma forma ou de outra, acesso aos capitais culturais, geralmente proporcionados inicialmente pela posse de capital econômico. 
Além disso, percebe-se que a partir da implantação da Escola Normal em Ponta Grossa em 1924, a participação das mulheres, evidenciada por artigos, avisos, recados, textos diversos, assim como pela constatação da ocupação de outros cargos por elas, aumentou consideravelmente na década de 1930. Com isso, podemos indicar a relevância que a educação, compreendida de forma ampla, teve na participação social das mulheres em Ponta Grossa. Referimo-nos aqui especificamente à possibilidade de formação educacional institucionalizada pela Escola Normal, preconizada como espaço de formação feminino por excelência (SOUSA, 2013).

Sobre isso, em uma reportagem cujo título era "A mulher desperta", publicada em 25 de outubro de 1920, fica claro que as mulheres aos poucos foram se inserindo nos diversos espaços sociais, participando das discussões que se desenvolviam na sociedade das décadas de 1910 a 1930, expondo suas opiniões e lutando pela aquisição de novos direitos que elas acreditavam que mereciam alcançar. Dessa forma, na transcrição dessa reportagem pode-se ler:

\begin{abstract}
A mulher desperta
Como está no conhecimento publico, algumas senhoras bem intencionadas formaram o projecto de organisar-se um gremio feminino de protecção ao sexo e de desenvolvimento moral e intellectual de suas associadas. [...]. Ella acorda agora do mutismo intellectual em que a conservou, durante seculos, a nefasta ministração dos dogmas, capciosamente inventados pela theologia. Começa a se convencer de que para servir a Deus e á humanidade não é preciso ajoelhar-se deante de ídolos, nem no tribunal iniquo do confessionário, nem sobre as lages estioladoras de um claustro escuro. [...]. (DC, 25/10/1920).
\end{abstract}

Desse modo, procuramos perceber a relevância do jornal Diário dos Campos/O Progresso no sentido de proporcionar condições de formação de uma identidade feminina, compreendendo esse processo formativo como amplo, indo além da educação institucionalizada, mas abarcando também os processos de tomada de decisão e vivência da cidadania. Sobre isso, uma entrevista do jornalista Raul Gomes com Anita Philipovsky explicita essa "nova" condição feminina:

Raul Gomes: Há em Ponta Grossa um meio literário?

Anita Philipovsky: Creio poder responder afirmativamente. Não constituem esse meio um elevado número de elementos, porém, entre eles, alguns bastante e merecidamente considerados no mundo intelectual paranaense, e que com dedicação digna de louvor mantêm a folha literária que aqui se publica, e outros, que ainda principiantes, mas que pelo talento e aplicação ao estudo prometem um futuro bastante lisonjeiro para a literatura pontagrossense.

Raul Gomes: Existem, como parte integrante, elementos femininos? Anita Philipovsky: Sim...

Raul Gomes: Esses elementos femininos são muitos? 
CAMPAGNOLI, K. R.

\begin{abstract}
Anita Philipovsky: Infelizmente não. Há mesmo um número muito limitado de moças que escrevem. As senhoritas ponta-grossenses dedicam-se com preferência à musica e à pintura, e creio que se pode atribuir esse desamor às letras, à crítica, que essa arte, mais que todas as outras, está sujeita.

Raul Gomes: Podeis citar os nomes que vos ocorrem?

Anita Philipovsky: Marianna Duarte, Giovanina Bianchi, Josephina Rodrigues, Cordelia do Amaral, Daluz Pupo, Maria Luiza Xavier e Herminia Cordeiro são os nomes que agora me vêm à lembrança. $(O$ Progresso, 10/12/1912).
\end{abstract}

Assim, percebemos que no jornal Diário dos Campos, em meio a reportagens, notícias e propagandas de cunho mais tradicional que representavam as mulheres nos papéis de mãe, esposa e professora, foram surgindo outras notícias que retratavam as mulheres por um viés mais autossuficiente e emancipado. Pode-se conjecturar que essa autonomia não se deu de forma completa já nos primeiros tempos, devendo, portanto, ser compreendida como um processo longo, moroso e repleto de resistências, tencionamentos e embates. No entanto, alguns avanços já puderam ser visíveis, uma vez que muitas discussões giravam em torno do fato de as mulheres adquirirem maior liberdade de escolha na educação, como um todo, mas também na cultura e principalmente na política, com a conquista do direito ao voto.

Um exemplo de perfil feminino mais progressista é o caso da aviadora Anésia Pinheiro Machado, citada na edição de 07 de setembro de 1922, explicitando a atuação de uma mulher em um campo ocupado majoritariamente por homens, conforme também destacado por Perrot (1998). Esse fato ocorreu no Rio de Janeiro e a notícia foi reproduzida pelo DC. Assim, apesar de o caso da aviadora Anésia não estar relacionado diretamente com a cidade de Ponta Grossa, podemos refletir sobre o fato de que a notícia de uma mulher pilotar sozinha um avião, no ano de 1922, possivelmente tenha causado algum sentimento - de espanto, de admiração, de crítica etc. - nos sujeitos que leram essa reportagem em Ponta Grossa. A circulação dessa notícia demonstra que uma mulher, em alguma região, perto ou longe, estava se atrevendo a exercer uma atividade até então nunca imaginada para uma mulher. Assim, a partir desse acontecimento, a ideia de possibilidade, de ousadia, de iniciativa, de encorajamento e também de atrevimento poderia, de repente, estimular sonhos e anseios nos leitores, mulheres talvez.

Concomitantemente aos avanços das discussões sobre a autonomia e os direitos das mulheres, outras notícias surgiram no jornal Diário dos Campos na contramão desse processo. Como exemplo, em uma nota de 22 de julho de 1933, menciona-se a criação de uma "universidade fundada para evitar os males do divórcio". Além disso, a manchete da reportagem dizia: "Onde as mulheres aprendem a tornar felizes seus futuros esposos", numa clara alusão ao papel secundário das mulheres no mundo, sugerindo que elas deveriam apenas preparar-se para agradar seus esposos, resignando-se muitas vezes e anulando seus sonhos, anseios e vontades. Além disso, esse texto expressa claramente o papel fundamental que a mulher deveria assumir nesse contexto, tornando-se a "rainha do lar", esforçando-se para diminuir as frustrações dos maridos, frustrando-se elas próprias em prol do bem-estar da família. 
Ao mesmo tempo que a mulher ia galgando espaços sociais importantes em alguns setores, outras discussões, em outros campos, ainda se desenvolviam sobre a legitimidade de participação da mulher. Um exemplo disso, veiculado na edição de 21 de fevereiro de 1933, versa sobre a questão de a mulher poder ser jurada nos ambientes jurídicos. No caso específico, um juiz - "dr. Julio Abelardo Teixeira" - envolvido nesta questão, justificava que era contrário à participação da mulher em julgamentos, alegando que elas agiriam com sentimentalismo exacerbado, comprometendo a análise imparcial sobre os julgados. Esse juiz fazia referência à ideia de mulher como sexo frágil, num habitus bastante difundido na época. Martins (2004) também faz menção ao ideário masculino que pregava a representação da mulher como emocionalmente instável, portanto, inapta para participar de situações dessa modalidade.

As discussões sobre as mulheres poderem ser juradas ou não, nos julgamentos do setor judiciário, como fóruns, tribunais e instâncias similares, nos levam a refletir sobre muitos aspectos. Por exemplo: inicialmente, devemos considerar que, nos júris populares, os jurados votam conforme seus próprios entendimentos e concepções, em decisões individuais tomadas após todos os personagens envolvidos em um julgamento apresentarem seus pontos de vista, constituindo-se, portanto, em um voto livre, autônomo e sem necessidade de justificativa. Desse modo, se as mulheres não participam desses momentos, então os ambientes jurídicos devem ser compreendidos como instâncias de poder eminentemente masculinas, em que os julgamentos e destinos de homens e mulheres são decididos apenas por eles, sob a justificativa de que as mulheres não são capazes de julgar com coerência, pois são excessivamente emotivas.

Dessa forma, constata-se que aos poucos o DC foi cedendo espaço às mulheres, informando à sociedade que tinha acesso a esse periódico, especialmente as representantes do gênero feminino, sobre as conquistas nos espaços públicos que elas iam adquirindo no Brasil e no mundo, ressaltando seus feitos no campo do trabalho, da política, das artes, da educação, entre outros. Desse modo, podemos considerar que o jornal Diário dos Campos se constituiu como uma opção de formação de uma identidade para as mulheres de Ponta Grossa, permitindo a circulação em suas páginas de novas ideias e de novas possibilidades para elas, demonstrando que novos horizontes, aqui e ali, estavam se descortinando. Com isso, talvez o DC pudesse encorajar outras mulheres, apresentando às leitoras desse periódico de uma cidade do interior possíveis alternativas para vivenciarem novos papéis sociais.

\section{CONSIDERAÇÕES FINAIS}

Este artigo fundamenta-se em uma pesquisa documental com abordagem qualitativa, que teve como fonte o jornal Diário dos Campos, periódico centenário da cidade de Ponta Grossa - Paraná, elencando como período de análise o interstício compreendido entre as décadas de 1910 a 1930. Objetivou-se discutir algumas possibilidades de formação da identidade das mulheres por meio da imprensa, constatando a progressiva participação delas em diversos espaços públicos, até então pouco comuns para o gênero feminino. 
Constatou-se que os artigos analisados, e que se relacionavam às mulheres, privilegiaram as temáticas referentes às possibilidades de formação educacional, cultural e profissional, envolvendo aspectos da arte e da cultura, além da busca de novos direitos políticos e sociais, rompendo barreiras e estereótipos, construindo, assim, novos habitus para o gênero feminino, indo além de uma formação identitária prescrita pelos homens.

Por meio das páginas do jornal Diário dos Campos observou-se o protagonismo cultural do gênero feminino em vários campos, constituindo-se em um marco importante da historiografia educacional das mulheres em Ponta Grossa. No entanto, constatou-se que o engajamento e empoderamento femininos evidenciados no DC ocorreram apenas para uma parcela pequena das mulheres, ou seja, as que possuíam capital econômico, cultural e social.

Artigo recebido em: 08/07/2020 Aprovado para publicação em: 03/11/2020

\section{POSSIBILITIES OF FORMATION A FEMALE IDENTITY FROM THE PAGES OF THE JOURNAL DIÁRIO DOS CAMPOS - FROM 1910 TO 1930}

ABSTRACT: The objective of this article is to discuss the formation of a female identity, by analyzing publications from the Diário dos Campos newspaper, a local centenary periodical, approaching the historical context of the decades from 1910 to 1930. From documentary analysis, with qualitative approach, we proceeded to understand how reports, articles and other materials of this newspaper referred at women, reflected on the formation possibilities provided by the female public in this specific historical context. It appears that the female engagement and empowerment evidenced in this journal occurred only for a small portion of women, that is, those who had economic, cultural and social capital, with the formation of some habitus that favored these behaviors.

KEYWORDS: Women's education. Feminine gender. Education. Female formation.

POSIBILIDADES DE FORMACIÓN DE UNA IDENTIDAD FEMENINA EN LAS PÁGINAS DEL PERIODICO DIÁRIO DOS CAMPOS - 1910 HASTA 1930

RESUMEN: El propósito de este artículo es discutir la formación de una identidad femenina, analizando las publicaciones del periódico Diário dos Campos, un diario local centenario, que aborda el contexto histórico de las décadas de 1910 a 1930. A partir del análisis documental, con un enfoque cualitativo, se buscó comprender cómo los reportajes, artículos y otros asuntos del referido diario fueron dirigidos a las mujeres, reflexionando sobre las posibilidades de formación que se ofrecen al público femenino en este contexto histórico específico. Parece que el involucramiento y empoderamiento femenino evidenciado en este periódico ocurrió solo para una pequeña porción de mujeres, es decir, aquellas que tenían capital económico, cultural y social, con la formación de algún habitus que favorecía estos comportamientos.

PalaVRas ClaVE: Education de la mujer. Género femenino. Educación. Formación femenina. 


\author{
FONTES \\ Jornal O Progresso (1907-1013) \\ Jornal Diário dos Campos (1913-1924) \\ Jornal Diário dos Campos (1932-1937)
}

\title{
REFERÊNCIAS
}

ALMEIDA, J. S. de; SOARES, M. Mudaram os tempos; mudaram as mulheres? memórias de professoras do Ensino Superior. Revista Avaliação, Campinas/Sorocaba, v. 17, n. 2, p. 557-580, jul. 2012.

BOTELHO, A.; SCHWARCZ, L. M. (Orgs.). Cidadania, um projeto em construção: memórias, justiça e direitos. Rio de Janeiro: Companhia das Letras, 2013. (Coleção Agenda Brasileira).

BOURDIEU, P. O poder simbólico. Tradução de Fernando Tomaz. Rio de Janeiro: Editora Bertrand Brasil, 1989.

BOURDIEU, P. Razões práticas: sobre a teoria da ação. 9. ed. Campinas: Papirus, 2008.

BOURDIEU, P. A dominação masculina: a condição feminina e a violência simbólica. Tradução de Maria Helena Kühner. 4. ed. Rio de Janeiro: Best Bolso, 2017.

CHAVES, N. B. A cidade civilizada: discursos e representações sociais no jornal "Diário dos Campos". Curitiba: Aos Quatro Ventos, 2001.

CINE Players. Filme "Mulher sem algemas". Disponível em: https://www.cineplayers.com/filmes/mulher-sem-algemas. Acesso em: 27 maio 2019.

DUARTE, C. L. Literatura feminina e crítica literária. Travessia, Florianópolis, n. 21, p. 1523, 1990.

FREIRE, V. L. B.; PORTELLA, A. C. H. Mulheres pianistas e compositoras, em salões e teatros do Rio de Janeiro, Cuadernos de Música, Artes Visuales y Artes Escénicas, Bogotá, v. 5, n. 2, p. 61-78, jul./dez. 2010.

MARTINS, A. P. V. Visões do feminino: a medicina da mulher nos séculos XIX e XX. Rio de Janeiro: Editora FIOCRUZ, 2004. 
CAMPAGNOLI, K. R.

MARTINS, A. P. V. Não somos feministas de colarinho e gravata: modernidade e conservadorismo na trajetória biográfica de Rosy de Macedo Pinheiro Lima (1914-2001). In: COSTA, H.; PEGORARO, J. W.; STANCZYK FILHO, M. (Orgs.). O Paraná pelo caminho: histórias, trajetórias e perspectivas. Curitiba: Máquina de Escrever, 2017. p. 184-219. (Coleção Movimentos, v. III).

MOTT, M. L. Estudos biográficos e filantropia: uma reflexão a partir da trajetória de vida de Pérola Byington, Revista Gênero, Niterói, v. 3, n. 2, p. 21-41, 2003.

OLIVEIRA, L. L. Entre a crítica de Anita Philipovsky (1886-1967) e as contradições do Estado: a história da educação das mulheres em Ponta Grossa na Primeira República. 2018. 125 f. Dissertação (Mestrado em Educação) - Universidade Estadual de Ponta Grossa, Ponta Grossa, 2018.

PERROT, M. Mulheres públicas. Tradução de Roberto Leal Ferreira. 2a reimpressão. São Paulo: Fundação Editora da UNESP, 1998.

SANTOS, L. P. B. Mulheres e revistas: a dimensão educativa dos periódicos femininos Jornal das Moças, Querida e Vida Doméstica nos anos 1950. 2011. 164 f. Dissertação (Mestrado em Educação) - Universidade do Estado do Rio de Janeiro, Rio de Janeiro, 2011.

SCOTT, Joan Wallach. Gênero: uma categoria útil de análise histórica. Educação e Realidade, Porto Alegre, v. 20, n. 2, p. 71-99, jul./dez. 1995.

SOUSA, N. L. O projeto republicano para a educação no Paraná e o processo de (des) mistificação de Júlia Wanderley. 2013. 121 f. Dissertação (Mestrado em Educação) Universidade Estadual de Ponta Grossa, Ponta Grossa, 2013.

TELLES, N. Rebeldes, escritoras, abolicionistas. Revista de História, São Paulo, n. 120, p. 73-83, jan./jul. 1989.

TELLES, N. Escritoras, escritas, escrituras. In: DEL PRIORE, M. (Org.). História das mulheres no Brasil. 10. ed. São Paulo: Contexto, 2015. p. 401-442.

TRINDADE, E. M. de C. Clotildes ou Marias: mulheres de Curitiba na Primeira República. Curitiba: Fundação Cultural, 1996.

VIEIRA, C. E. Jornal diário como fonte e como tema para a pesquisa em História da Educação: um estudo da relação entre imprensa, intelectuais e modernidade nos anos de 1920. In: OLIVEIRA, M. A. T. de (Org.). Cinco estudos em história e historiografia da educação. Belo Horizonte: Autêntica, 2007. p. 11-40.

WOELLNER, A. M. A voz da mulher na literatura. Revista de Literatura, História e Memoria, Cascavel, v. 3, n. 3, p. 9-34, 2007. 
Karina Regalio Campagnol: Doutorado em andamento em Educação. Mestrado em Educação pela Universidade Estadual de Ponta Grossa (2020), na linha de História e Política Educacionais. Especialização em Pedagogia - Gestão e Docência pela Pontifícia Universidade Católica do Paraná (2020). Graduação em Licenciatura em Pedagogia pela Universidade Estadual de Ponta Grossa (2017).

Orcid: https://orcid.org/0000-0002-6068-7073

E-mail: karinaregalio@hotmail.com

Este periódico utiliza a licença Creative Commons Attribution 3.0, para periódicos de acesso aberto (Open Archives Iniciative - OAI). 